Article

\title{
Artificial Intelligence, Transport and the Smart City: Definitions and Dimensions of a New Mobility Era
}

\author{
Alexandros Nikitas ${ }^{1, *(1)}$, Kalliopi Michalakopoulou ${ }^{1}\left[\right.$, Eric Tchouamou Njoya ${ }^{1}$ and \\ Dimitris Karampatzakis 2 (D) \\ 1 Department of Logistics, Marketing, Hospitality and Analytics, Huddersfield Business School, \\ University of Huddersfield, Huddersfield HD1 3DH, UK; kalliopi.michalakopoulou@hud.ac.uk (K.M.); \\ e.njoya@hud.ac.uk (E.T.N.) \\ 2 Department of Computer Science, International Hellenic University, Agios Loukas, 65404 Kavala, Greece; \\ dkara@cs.ihu.gr \\ * Correspondence: a.nikitas@hud.ac.uk; Tel.: +44-1484-471-815
}

Received: 8 February 2020; Accepted: 28 March 2020; Published: 1 April 2020

check for

\begin{abstract}
Artificial intelligence (AI) is a powerful concept still in its infancy that has the potential, if utilised responsibly, to provide a vehicle for positive change that could promote sustainable transitions to a more resource-efficient livability paradigm. AI with its deep learning functions and capabilities can be employed as a tool which empowers machines to solve problems that could reform urban landscapes as we have known them for decades now and help with establishing a new era; the era of the "smart city". One of the key areas that AI can redefine is transport. Mobility provision and its impact on urban development can be significantly improved by the employment of intelligent transport systems in general and automated transport in particular. This new breed of AI-based mobility, despite its machine-orientation, has to be a user-centred technology that "understands" and "satisfies" the human user, the markets and the society as a whole. Trust should be built, and risks should be eliminated, for this transition to take off. This paper provides a novel conceptual contribution that thoroughly discusses the scarcely studied nexus of AI, transportation and the smart city and how this will affect urban futures. It specifically covers key smart mobility initiatives referring to Connected and Autonomous Vehicles (CAVs), autonomous Personal and Unmanned Aerial Vehicles (PAVs and UAVs) and Mobility-as-a-Service (MaaS), but also interventions that may work as enabling technologies for transport, such as the Internet of Things (IoT) and Physical Internet (PI) or reflect broader transformations like Industry 4.0. This work is ultimately a reference tool for researchers and city planners that provides clear and systematic definitions of the ambiguous smart mobility terms of tomorrow and describes their individual and collective roles underpinning the nexus in scope.
\end{abstract}

Keywords: artificial intelligence; smart city; smart transport; connected and autonomous vehicles; personal and unmanned aerial vehicles; mobility-as-a-service; internet of things; physical internet; industry 4.0

\section{Introduction}

In a time that is dictated, more than ever before, by a need to shift to a more sustainable techno-social paradigm to avoid the adverse repercussions of a resource-intensive and unthoughtfully opportunistic livability philosophy that does not look far in the future, Artificial Intelligence (AI) has the potential to provide a vehicle for transformation. AI is a concept that is defined as a system's ability to correctly interpret external data, to learn from such data and to use that learning to achieve specific goals and tasks through flexible adaptation [1]. AI is based on the development of autonomous 
agents that can reason and plan towards their goal without any built-in knowledge base of their environment [2]. AI holds the promise of making us healthier, wealthier and happier by reducing the need for human labour and by vastly increasing our scientific and technological progress [3]. Nowadays, AI has transformed our lives in many aspects, from semi-autonomous cars on the roads to robotic vacuums in our homes and arguably will continue to invade every area of our lives, from health care to education, entertainment and security, for the foreseeable future [4].

One of the prime areas where AI will make its most paradigm-shifting impact is transport. Examples of AI methods that are finding their way into the transport field include Artificial Neural Networks (ANNs), Genetic Algorithms (GAs), Simulated Annealing (SA), Artificial Immune System (AIS), the Ant Colony Optimiser (ACO), Bee Colony Optimisation (BCO) and the Fuzzy Logic Model (FLM) [5]. These AI interventions have potential applications for the vehicle, the infrastructure, the driver or transport user, and in particular, for how these interact dynamically to deliver a transport service that promotes user empowerment and supports human-machine interactions [6].

Since transport is the most decisive cornerstone for a city's functionality, development and prosperity, revolutionising transport transforms the concept of the city. Urban structure and transport system developments are closely connected as evidenced by theories like the urban land rent theory and location theory, which conceptualise the connection between transport and urban land use $[7,8]$. It is impossible to abstract the vision of the cities of tomorrow from that of the future configuration of their transport systems [9]. The provision of mobility solutions for battling congestion, pollution and environmental degradation through AI technology that is capable of providing better, faster, cleaner and cheaper ways to move around is the pillar, together with telecommunication and energy applications [10], of what we call smart cities and the way forward for urban science.

The concept of the smart city is far from being limited to the application of digital and cloud-based technologies to cities since it has creative, sustainable, strategic decision-making, integrating, knowledgegenerating and people-focused qualities, or as Albino et al. [11] describe it, a smart city is an "instrumented, interconnected and intelligent city". A smart city incorporates Information and Communication Technologies (ICT) to reduce costs, optimise resource consumption, improve interactivity and enhance the quality of life for its citizens [12]. Where once the lexicon of transport professionals and city planners centred upon sustainable urban transport and sustainable cities, this has now shifted in attention, or expanded, with reference to smart cities and smart urban mobility that is reflective of digital age possibilities [13]. This can be seen in the high number of smart city initiatives, city implementation projects and jointly-funded public research projects that have rapidly emerged across the world [14], especially in the mobility sector. The notion of smart cities is overarching in this work, and because of our future mobility angle, is primarily set to look into the context of policy prioritisation for sustainable urban growth via transport innovation, which as Kominos et al. [15] recognises, is still a largely unknown field. As with any socio-technical transition, the shift to an AI-based mobility paradigm creates critical questions to be posed in terms of how the transition will be managed [16] and what will be those interventions that will define this transition.

This paper provides a novel conceptual contribution that tries to answer these questions by describing some of the key transport components that are projected to be central to the AI-centric smart city of the (near?) future. The paper is ultimately a research lexicon defining terms and their dimensions that reflect and affect the new autonomous, connected, shared and digitised mobility paradigm of tomorrow. More specifically the paper thoroughly discusses the nexus of AI, transportation and the smart city by covering interventions referring to Connected and Autonomous Vehicles (CAVs), Unmanned and Personal Aerial Vehicles (UAVs and PAVs) and Mobility-as-a-Service (MaaS), but also the Internet of Things (IoT), Physical Internet (PI) and Industry 4.0, which are three initiatives that may impact transport in direct or indirect ways and are critical parts of the smart city agenda.

Automated driving is widely considered to represent a technology that could signal an evolution towards a major change in (car) mobility $[17,18]$. CAVs are the ultimate manifestation of AI in the field of transport; AI algorithms and machine learning (ML) functions are the tools that could replace 
human intervention and "drive" CAVs instead [19]. CAVs are projected to have the ability to introduce eco-driving and energy-saving functions, enhanced safety and security standards, better road space allocation and traffic congestion management and replace time spent driving with time that can be utilised for more productive activities [20]. However, despite their massive hype, CAVs still present more unanswered questions than definitive answers [21]. UAVs, drones and PAVs have recently emerged as a viable alternative to manage problems that primarily arise in the areas of visual monitoring and traffic surveillance [22,23]. Fully autonomous UAVs and PAVs in the future will be of massive importance for logistics and also for moving people; they are expected to reshape travel patterns as we have known them for decades now by expanding vertically the urban landscape and transport network of future cities. MaaS, a very recent transport concept with limited applications of partial implementation thus far, is promising digital packages of personalised mobility that will replace privately owned vehicles and optimise the use and combination of several mobility alternatives. MaaS will be enabled by powerful AI algorithms that will provide holistic travel planning, booking and ticketing, and real-time information services customised and tailored to each consumer's needs. MaaS can maximise its potential if it incorporates, as a complementary option to its public transit elements, the use of CAVs by way of car-sharing and ride-sharing schemes [21]. Technology trends referring to an AI-centric smart city, which could affect (or be affected by) future mobility, such as the IoT, PI and Industry 4.0, are becoming increasingly relevant [24] and will also be considered through a transport-oriented lens herein. This is because the IoT will enable unprecedented connectivity levels between users and transport modes; the PI will revolutionise freight transport optimisation through digital, automated, interconnected and big data technologies; and Industry 4.0, the backbone of tomorrow's market productivity, depends on smart transport.

Henceforth, the paper provides the framework of the research methodology employed, a description of the aforementioned initiatives (a section for each of them) and a final section that serves as a lexicon for the concepts considered in the previous sections. This last part of the paper is also about elaborating conclusions that bring all the different pieces of the complicated smart urban mobility's puzzle together and deliver some key recommendations for city scientists, policymakers, transport and urban planners and an agenda for future research directions.

\section{Research Methodology}

This work is the result of a systematic literature review that examined the peer-reviewed literature published in English for the nexus of AI, transport and the smart city. The Scopus search which underpinned the approach was limited strictly to journal papers as a quality measure. The first paper ever recorded that considered this research agenda was published as early as 1984 but the vast majority of the papers produced ( $>90 \%$ ) have been published during the last decade; these papers were the most relevant ones for our task. Furthermore, our analysis includes a few references outside this search highlighting peripheral, but yet important, aspects of the diverse agenda covered that were not picked up by the Scopus searching engine but were deemed necessary to support some of the key arguments made.

Four different searches were undertaken using Scopus. All the possible combinations of the key elements of the study were explored to make sure that most of the synergies reported in a diverse and multidisciplinary literature between AI, transport and the smart city would be identified and examined in our analysis. The search "artificial intelligence" AND "transport" resulted in identifying 873 papers, the search "transport" AND "smart city" returned 594 papers and the search "artificial intelligence" AND "smart city" shortlisted 201 papers fulfilling our search criteria. The most important search of all, bringing together "artificial intelligence" AND "transport" AND "smart city", confirmed our rationale for writing this manuscript; only 18 papers were found to be discussing all three elements and their interrelations. Only two of those papers had some direct, but partial, relation with the explicit goals of the present work $[25,26]$, while the other papers were more computing- and engineering-oriented or focused on very isolated aspects of the nexus discussed. One finding that was particularly interesting 
was the availability of conference papers when compared with journal papers; for the search "artificial intelligence" AND "smart city", we ended up shortlisting 201 papers but the number of research conference papers were four times that many.

Figure 1 provides the results of our Scopus search for the subject combinations discussed above and also includes quantification of the sources identified. Due to the large number of journal outputs that we identified, Figure 1 lists only the top five journals (in terms of the number of papers referring to our four key searches) per combination only. We did not necessarily end up reviewing these journal papers per se since our analytic criteria (explained below) were primarily quality- and relevance-related.

We also searched for combinations of our study's key elements (i.e., the interventions discussed per se). More specifically, "CAVs" AND "UAVs" returned zero papers, "CAVs" AND "PAVs" returned three papers, "CAVs" AND "MaaS" returned 13 papers, "MaaS" AND “UAVs" returned 46 papers and "MaaS" AND "PAVs" returned two papers. Furthermore, "CAVs" AND “IoT" returned 29 papers, "UAVs" AND "IoT" returned 169 papers, "PAVs" AND "IoT" returned three papers, "MaaS" AND "IoT" returned 174 papers, "PI" AND "CAVs" returned nine papers, "PI" AND "UAVs" returned 28 papers, "PI" AND "PAVs" returned zero papers, "PI" AND "MaaS" returned one paper, "Industry 4.0" AND “CAVs" returned one paper, "Industry 4.0" AND “MaaS" returned one paper, "Industry 4.0" AND "UAVs" returned six papers and "Industry 4.0" AND "PAVs" returned no papers. The majority of these papers were already covered in our initial and more generic search approach outlined in Figure 1. Again, most of them did not align well with the specific research agenda of our paper but were instead rather irrelevant, with most of them being very technical.

At the end, each of the four authors read the 1668 titles of the papers identified, subsequently reviewed more than 500 abstracts of papers that were closer to the scope of the present work and finally generated an independent structured literature review based on those articles identified as more relevant in sketching the picture of the AI-centric transport system that will underpin the smart cities of tomorrow. The four authors then compared and synthesised their independent review drafts to develop a unified "bigger-picture" narrative, which was a process headed by the lead author. The paper in its finalised form includes references to 133 studies, all of which were read from cover to cover. The selection of material was made based on the subject-specific relevancy of the research output, the host journal impact factor and each paper's impact as measured by the number of its citations. While the authors acknowledge an element of subjective criteria in the choice of the material used (selection bias is part of human nature), this systematic literature review process was adopted to minimise bias and improve the richness, fluidity and value of the content. The authors, each of them with distinct scientific backgrounds and research priorities and values, acted as checks and balances to each other and highlighted key points of the literature that a single author could not have captured in the same interdisciplinary and vivid way.

To support their bibliographic work, the authors reviewed evidence from a selection of representative international case study examples and media news to recognise the success or failure of very early (or pilot applications of) AI-centric smart city transport practices. This adds an empirical dimension to the paper's theoretical and conceptual merits that may directly inform academics, city scientists, policymakers, mobility providers and urban planners about some of the lessons available to them that could fuel a positive paradigm-shifting transition governed by AI applications. A similar two-step methodological approach involving this structure has been used in the lead author's previous work with significant success [7], which is something that gives an extra layer of validity to the present study.

The work is also not about forecasting only the "wins", "advantages" and "positive distributional impacts" of the listed AI-centric mobility initiatives, but also develops an in-depth understanding of the not-so-often-studied barriers, concerns and unintended consequences of this transformation process. Change, despite how good it may be, is neither easy nor straightforward; strategic planning and implementation are of critical importance for transitioning to the era of the "smart city". 


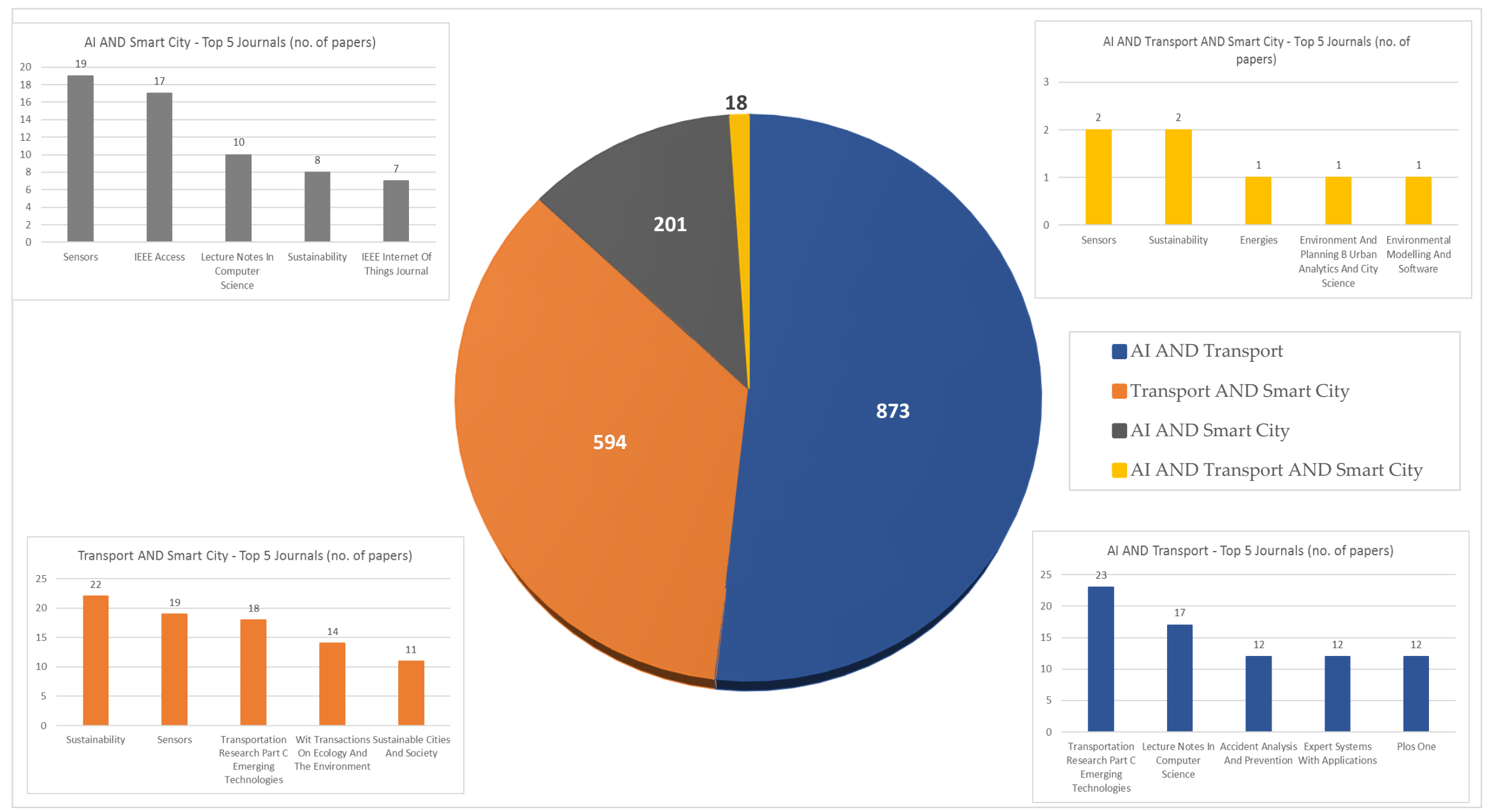

Figure 1. Visualising the systematic literature review: Scopus search results per subject combination and quantification of the bibliographic sources. 


\section{Connected and Autonomous Vehicles}

The automobile has changed the earth's natural and built environment more than any other invention in the history of humankind by reshaping cities and economies [27]. Connected and Autonomous Vehicles (CAVs) are the natural successors of conventional cars with motion and action capabilities that do not require any sort of conductor (driver) or teleoperation control [28], along with connectivity functions that make them proactive, cooperative, well-informed and coordinated since they can "talk" with their surrounding environment [29] and eventually with everything and everyone when the IoT will be in place. CAVs will transform mobility provision, transport networks and road infrastructure, passing the vehicle control and driving responsibilities from humans to machines with enormous $\mathrm{AI}$ and wireless connectivity capacities. CAVs are projected to be the next gold standard of mobility, transforming cars and city development as a whole through the use of AI from what they are conceived of as today.

The automotive industry will have to transform, by changing entirely their production lines, as CAVs are very different from the conventional human-driven vehicles. The companies actively working on the development of CAVs and conducting trials with various degrees of success (including a few life-losing failures) is a mix of traditional car manufacturers, ride-hailing and intelligence companies namely: Audi, Baidu, BMW, Daimler, Delphi, Didi Chuxing, Ford, General Motors, Honda, Huawei, Hyundai, Jaguar Land Rover, Lyft, Magna, Mercedes-Bosch alliance, Microsoft, nuTonomy, PSA, Renault-Nissan alliance, Samsung, Tesla, Toyota, Uber, Volkswagen Group, Volvo, Waymo (Google's self-driving cars project), ZF and Zoox. Intelligence provision powerhouses like Google and ride-hailing giants like Uber, not considered at present as typical vehicle manufacturers, will radically change the dynamics of the industry becoming new entrants in a more versatile automotive market, where ICT will be a difference-making competitive advantage. The automotive industry may also be forced to adopt new business models for sales that will prioritise shared use over private ownership if smart cities decide to actively promote sustainable growth via car ownership reduction. USA, Great Britain, Australia, New Zealand, Germany, Sweden and China are the leading countries trying to position themselves in the epicentre of the CAVs "explosion" working on CAV-enabling legislation and investing massively in research and development activities including pilots and trials.

Every revolution promises a spirit of optimism and significant changes and CAVs are a prime example of this [30]. CAVs intend to generate numerous benefits, such as creating more free time (since the average driver spends the equivalent of six weeks driving per year); enhancing traffic safety and accident prevention; improving accessibility, comfort and in-vehicle riding experience; potentially making it easier for policymakers to prioritise car-sharing and ride-sharing business models; and reducing road traffic congestion, environmental degradation, air pollution, noise nuisance and social exclusion for those currently unable to drive. At the same time though, there are also some concerns, usually less communicated and studied, about the increased vulnerability to hacking, software and hardware flaws; loss of privacy and travel data exploitation; liability allocation challenges; increased car usage from more populations and unoccupied vehicles; increased traffic accident, congestion and emission rates during the transition period when CAVs will co-exist with simpler AVs, semi-autonomous and conventional vehicles; and behavioural adaption, situational awareness and user resistance problems. These opportunities and challenges have been recorded in the literature [17,19-21,31-34], but have rarely been grouped in a single source. Table 1, based on these readings, summarises the key opportunities and challenges reflecting and affecting the full-scale launch of CAVs and their future usage. 
Table 1. Opportunities and challenges referring to the implementation, uptake and usage of Connected and Autonomous Vehicles (CAVs).

\begin{tabular}{|c|c|}
\hline Potential Benefits to Society and Users & Potential Concerns for Society and Users \\
\hline $\begin{array}{c}\begin{array}{c}\text { Eliminate the human error factor from driving leading to traffic safety and accident } \\
\text { prevention gains }\end{array}\end{array}$ & Ambiguity for responsibility in accidents and damage scenarios \\
\hline Improved traffic security due to more and easier surveillance, monitoring and control & Increased vulnerability to software and hardware flaws and cybersecurity threats \\
\hline Reduced traffic congestion due to more efficient mobility and parking management & Extra car trips may be generated from more users and unoccupied vehicles \\
\hline Time savings due to efficient routing, platooning and stabilised traffic flow & Communication problems with non- or partially autonomous vehicles and other modes \\
\hline Environmental benefits including less $\mathrm{CO}_{2}$ and greenhouse gas emissions & Susceptibility of the car's navigation system to adverse weather conditions \\
\hline Decreased noise nuisance since CAVs will have quieter engines & Lack of trust in new technologies and agencies responsible for running CAVs \\
\hline Reduced energy consumption and fossil fuel dependence - CAVs will eco-drive & Privacy issues and loss of personal space \\
\hline Increased productivity - people can use in-vehicle time to do productive activities & $\begin{array}{l}\text { Employability threats - driving-based jobs will cease to exist and therefore reskilling labour } \\
\text { would be necessary }\end{array}$ \\
\hline Huge car-sharing and ride-sharing potential & Likely loss of "ownership" rights - people like or are used to privately owned vehicles \\
\hline Significant demand-responsive potential & Possible blow to public transport services as we know them \\
\hline Cost minimisation for logistics, taxi and ride-sourcing companies and their customers & High-cost investments in advanced road infrastructure suitable for the needs of CAVs \\
\hline Less need for parking, which will free up public space for other more people-focused uses & Rural inequalities if CAVs become an urban only scenario due to cost \\
\hline Fewer layers of social exclusion - less age, disability and skill barriers to "drive" a vehicle & $\begin{array}{l}\text { Inequity issues if CAVs end up becoming expensive and over-complicated privately } \\
\text { owned machines }\end{array}$ \\
\hline Smaller enforcing and policing requirements & Need for an entirely new road transport regulations system and traffic code of practice \\
\hline Fewer requirements for road signage & Moral issues - can an algorithm decide who dies in an unavoidable crash? \\
\hline Reduced insurance premiums & User resistance to giving up driving control \\
\hline Smoother rides due to less acceleration and deceleration and steadier speeds & Behaviour adaptation problems - change takes time and generates dissatisfaction \\
\hline More cabin space - there is no need for a steering wheel & Loss of driving skills and situational awareness \\
\hline More relaxed travelling - more time to sleep, eat, play and have fun & Loss of "freedom" and "joy" that are part of the human driving experience \\
\hline
\end{tabular}


CAVs, despite technological breakthroughs, a wealth of promised benefits and million miles driven automatically in segregated and controlled situations across the world, may not be easily integratedable in our urban transport systems as yet. This is a long process that could take many years before fully in play [20]. This is because the introduction of these vehicles is accompanied by uncertainties in their effects on the car-sharing market and land use patterns but more importantly in how the public formulates opinions regarding benefits and concerns [35]. An unconditional, technology-driven introduction of CAVs could be in conflict with social and environmental sustainability objectives, ignoring the fact that the transport system is a complex socio-technical system which calls for joint optimisation of both the technical and societal sub-systems [36]. A techno-fix cannot be a panacea since technology is only one of the several tools in the toolbox of mobility $[19,32,37]$, therefore the revolution of CAVs should be underpinned by legislative, moral, educational, business and social engagement frameworks that set out a clear modus operandi.

It is also expected that CAVs might have a wider role to play if they are, as they should be, designed to be a powerful intervention with sustainability merits in environmental, economic and social terms; a role that is beyond the traditional automobility regime of today. They need to evolve to a strong complementary piece to a more holistic mobility system that substitutes private ownership of cars (and to some respect some of their use) with multimodal mobility packages that are designed to promote alternative means of transport and have CAVs as a shared option on an 'as-needed' basis only [21]. $\mathrm{CAVs}$ need to become a strategic centerpiece of MaaS and not its alternative. CAVs will therefore need to co-function and create synergistic links with public transport instead of competing for space and ways of priority. Transit Oriented Development (TOD) employing CAVs as first- and last-mile solutions and neighbourhood feeders to mass transit systems should be the ideal development scenario from an urban and land use perspective as a strategy that will not allow travel behaviour to become disproportionally car-centric. Bringing cars and public transport together, even in their automated future formats, may be an uneasy union because of their traditionally contradictory roles but future policy and planning efforts need to assist with balancing tensions and achieving the optimum blend of the two [7]. CAVs also need to be cleaner than ever before. Becoming electric is an option provided that the electricity will be produced by renewable energy sources and thus will be non-polluting as Kougias et al. (2019) [38] and Kougias et al. (2020) [39] strongly recommend for the right electromobility model. CAVs need to be autonomous and connected but they should also be strongly linked to electrification and shared usage. The synergistic effects between automation, connectivity, electrification and shared use can multiply significantly the benefits of CAVs as also noted by a relevant study [17].

However, the road to change is not straightforward. According to Nikitas (2020) [40] there are 10 areas of priority for CAVs policy and planning that need to be addressed for a smooth transition: technology, legislation, crisis and employment ethics, road infrastructure and land use, integration, traffic safety, cybersecurity and privacy, business models, traffic congestion and travel behaviour and finally acceptability, trust and customer readiness. Even if adequate answers are provided to all the above critical themes the future automobile fleet will be near homogenous no sooner than 2050 and only if CAV prices are reasonably low [41].

To date, 623 peer-reviewed journal articles discussing CAVs are accessible in the Scopus search engine. This number grows to 1688 research outputs when the search includes conference papers and book chapters, with more than three-quarters of these outputs being published from 2015 onwards. Nonetheless, the number of papers examining AVs is 20 times more. This is because connectivity is a latter trend, despite being associated with Intelligent Transportation Systems (ITS) for decades, that provides an additional dynamic communication function for a vehicle; AVs do not presuppose (or necessarily exclude) connectivity but primarily refer to the vehicle's ability to operate without human input. This number of available scientific outputs showcases the immense interest in researching an initiative with genuinely transformative powers. 


\section{Unmanned Aerial Vehicles and Personal Aerial Vehicles}

Unmanned Aerial Vehicles (UAVs), also commonly known as drones or unmanned aircraft systems, is a new powerful intervention that brings the revolution of $\mathrm{AI}$ and wireless technologies to air transport and aviation. With the emergence of high-power-density batteries, long-range and low-power micro-radio devices, cheap airframes and powerful microprocessors and motors, UAVs are tools with the potential to provide robust solutions towards the provision of improved military, policing and commercial services [42]. More specifically, UAVs can support tasks related to intelligence, surveillance and reconnaissance, border patrol, target identification and designation, counter-insurgency, attack and strike, civil security control, law enforcement applications, environmental monitoring, surveying and geospatial activities, remote sensing, aerial mapping, weather monitoring and meteorology, forest fire detection, traffic control, cargo transport, accident reporting, emergency search and rescue, disaster control and management, wireless coverage, cloud support and communication relays. Many of these tasks are barometers reflecting and affecting the day-to-day functionality and operability of a smart city.

UAVs can be broadly classified into two categories: fixed wing and rotary wing. Fixed-wing UAVs usually have a high speed and a heavy payload, but they must maintain continuous forward motion to remain aloft, and thus are not suitable for stationary applications like close inspection; meanwhile, rotary-wing UAVs, such as quadcopters, while having limited mobility and payload, can move in any direction and stay stationary in the air [43]. Challenges such as the lack of an onboard pilot to see and avoid other aircrafts and the wide variation in unmanned aircraft missions and capabilities must be addressed before the full integration of aerial technologies can take place in the smart city context [44]. Integrating UAVs with smart cities will create a sustainable economic environment and a peaceful place of living if challenges relating, on the one hand, with business considerations like ethics and privacy, cost, licensing, legislation and market adoption, and on the other hand, with technical issues, such as the proper use of wireless sensors, data communications, application management, resource training and allocation and power management are addressed adequately $[45,46]$. The key stakeholders for addressing these challenges all have a distinct role. Governing bodies work on introducing regulations, policies and operations guidelines to ensure the safe use of UAVs; researchers design models and architectures to build, integrate and deploy UAV applications; and the industry aims to develop and introduce value-added features to smart cities using UAVs [47].

Personal Aerial Vehicles (PAVs), Manned Aerial Vehicles (MAVs) or Personal Aerial Transport Systems (PATS) are emerging forms of mobility that promise to combine the best of ground-based and air-based transportation as a means of reducing urban congestion by making use of free space in the air [48]. PAVs will be an innovative mobility intervention capable of bridging the niche between scheduled airliners and ground transport by offering unprecedented levels of fast, on-demand urban mobility. If higher automation and falling prices are achieved, PAVs will soon be able to serve the urban settings of smart cities. Automation will allow PAVs to carry passengers with no piloting skills, making them much more accessible to anyone in practical terms. Infrastructure requirements, such as the number of landing and parking spaces, proper flying corridors, interaction with other modes and synergies with autonomous ground vehicles (PAVs and CAVs can benefit and complement each other), may allow PAVs to contribute significantly in the decrease of congestion and pollution if planned and implemented in a right way [49]. Nonetheless, despite innovation progress in the PAV concept development and related technologies, there are still key challenges that remain regarding public acceptance, traffic safety, expensive infrastructure, disaster management, trespassing and unnecessary surveillance, visual intrusion and excessive air traffic concerns $[47,50]$.

The applications of UAVs are still fairly limited, while PAVs are still in the infancy phase of their development trajectory despite claims from Germany's Volocopter that it will start trials of a flying taxi in Singapore in 2020 and Uber's plans to launch commercial flights in the USA by 2023 [51]. To date, we have more than 40,000 Scopus-indexed research outputs published almost solely on engineering and computer science related aspects of the two innovations. In the literature, both are projected to eventually morph to massive game-changers in urban mobility and facilitators of the smart city concept. 


\section{Mobility-as-a-Service}

Mobility-as-a-Service (MaaS) is a powerful notion, still in an embryonic stage of its development when it comes to a full-scale implementation, but immensely hyped up. MaaS in its purest future form is promising digital packages of personalised multimodal mobility that will replace privately owned vehicles through the use of an all-in-one smart online platform capable of providing integrated journey planning, booking, smart ticketing and real-time information services. If MaaS works as a real substitute to private automobile ownership and transforms car use to a service provided strictly on an as-needed basis, it has the potential to dramatically reduce the number of cars on the roads and thus deliver huge reductions in travel delays, air pollution, noise nuisance, energy consumption, and transport-related social exclusion, as well as provide benefits in terms of traffic safety and accident prevention, health and wellbeing, social cohesiveness, accessibility and household expenditure. It will also free up valuable living space from car traffic and car parking and will redistribute it to public and active transport, but also to other more human-centric built environment investments.

To date, 115 peer-reviewed journal articles are accessible in the Scopus search engine; the number grows to 259 research outputs if this includes conference papers and book chapters. The total body of this literature has been exclusively published from 2011 onwards, with more papers being issued every year. These studies cover many MaaS angles, including user experience [52-54], attitudes [55,56], integration with public transport [57-59], business models [60,61], travel behaviour [62,63], governance and policy [64,65], urban futures [66,67] and even Blockchain adaption [68].

These figures make it undeniable that the demand for MaaS research is not slowing down in the foreseeable future despite the vagueness behind MaaS implementation specifics and the lack of a truly cohesive and universal definition of the term. At present, there is a dichotomy between researchers and developers thinking of MaaS primarily as a ride- and car-sharing scheme facilitator and others advocating that MaaS should be a lot more than that. This means that given MaaS is not yet clearly defined and contextualised, it is still very difficult to assess how MaaS can affect travel behaviour and how it can help in transforming the future; or as Lyons et al. [69] notes: "there is very limited insight to date in terms of the behavioural impact of MaaS or its future potential". Regarding this context, Kamargianni et al. [70] highlights that it is important to study not only MaaS as a whole, but also its component elements (i.e., intermodal journey planners, payment methods, booking systems, real-time information and mobility packages) and their influence on consumers in terms of enablers or barriers.

Examples of early applications of MaaS with variable levels of reach, continuity and success so far include Whim in Helsinki and Birmingham; the pilot UbiGo in Gothenburg, which despite its success, ceased to exist in 2014 but as of 2019 has been relaunched in Stockholm; Moovel in Hamburg and Stuttgart; the year-long Smile pilot in Vienna, which has been replaced with the fairly successful WienMobil Lab; the Italy-wide myCicero; the Scottish project NaviGoGo, which was operational in Dundee and North Fife; the Hannovermobil in Hanover; Monpelier's EMMA (TaM); and ALD Move, which covers the whole of the Netherlands.

In theory at least, MaaS can maximise its potential if it incorporates in its very core the "cautious" use of CAVs (and even PAVs when available) strictly based on car-sharing or (even better) ride-sharing schemes. In this favourable (in sustainability terms) MaaS adaption scenario, CAVs can be first- and last-mile neighbourhood feeders to mass transit systems running in transport corridors that clearly prioritise or even enforce public transport use. If CAVs are shared as such, they might have the potential to blur the lines between public and private transportation services altogether [71] and could make MaaS appear as a less aggressive, controversial and restrictive mobility paradigm that, although it does not entirely fulfil its institutional rhetoric of "individual unfettered freedom" (as discussed in Pangbourne et al. [64]), makes a justifiable pro-sustainability compromise that includes, but is not centred around, car access. The AI-centric digital services of MaaS will need to mix and match multimodal trips on this premise.

Three key challenges affect the transition path to a MaaS-centric transport system. To identify the biggest barrier to MaaS success, it is necessary to concentrate on the pervasive influence of cultural 
practices and the need to facilitate a change of attitudes to ownership, not only for the more tech-savvy millennial generation, but for all people [72]. As attitudes towards owning versus leasing, renting and sharing transport vehicles are changing [73] because of sustainability pressures and increasing environmental awareness, MaaS could soon be more acceptable. Another problem that MaaS faces is the complexity of building up seamless collaborations between actors responsible for its introduction and operations management due to uncertainties in the business models [74] and/or due to conflicting interests between the mobility providers that need to be working together [21]. Policymaking, through research and development activities and trials, therefore needs to solve these cooperation problems by providing definitive answers regarding the optimum brand of MaaS since, as Pangbourne et al. [64] clearly suggest, promises of "efficiency" are not possible without government intervention. The third challenge that we might be facing is a scenario where MaaS will "help" public transport users and travelers with no driving license (or in the case of a CAV-based MaaS with no ability to drive) to create unsustainable travel behaviour habits by taking advantage of door-to-door solutions without using public transport. A modal shift to car-centric solutions will be everything that MaaS means to rectify.

\section{Internet of Things, Physical Internet, Industry 4.0 and Their Role in Smart Transport}

While the term Internet of Things (IoT) is increasingly used, there is no common definition or understanding today of what the IoT actually encompasses [75]. For many, the IoT evolved as a communication paradigm that envisions a near future in which the objects of everyday life will be equipped with microcontrollers, transceivers for digital communication and suitable protocol stacks that will make them able to communicate with one another and with the users such that they become an integral part of the Internet [76]. The main enabling factor of this promising paradigm is the integration of several technologies and communications solutions [77]. The IoT provides the ability to remotely monitor, manage and control devices, and to create new insights and actionable information from massive streams of real-time data [78]. It ultimately empowers an object to hear, see, listen, interpret and communicate at the same time [79]. The IoT uses an integrated cloud architecture of networks, software, sensors, human interfaces, 5G and data analytics for value creation [80].

The IoT is the technical backbone of smart cities and what makes them feasible; smart cities need to have three key features that the IoT can provide: intelligence, interconnection and instrumentation [81]. The IoT will complement the evolution of ITS based on the concept of object-to-object communication. ITS can provide the hardware element of the IoT with devices such as radio frequency identification (RFID) tags and readers, sensor technologies, positioning systems and emerging technologies to collect information about road conditions, traffic accidents, road repairs or the redesigning of avenues in the environment where they are placed [82]. The IoT, when fully operational and able to maximise its potential, will be the "glue" connecting the different components of the AI-centric travel eco-system, including CAVs, PAVS, UAVs and all the MaaS-operated modes in general, including non-motorised travellers.

Two more important facilitators of the AI-transport-smart city nexus will be the Physical Internet (PI, $\pi$ ) and Industry 4.0. The PI is a new concept for freight transportation and logistics aiming towards improving the economic, environmental and societal efficiency and sustainability of the way physical objects are moved, stored, realised, supplied and used all over the world [83,84]. It is an open global logistics system founded on physical, digital and operational interconnectivity through encapsulation, interfaces and protocols that will replace current analogue logistical models. Through the PI, freight will move via distributed, multimodal transportation networks in which transit sites aggregate containers from diverse origins to optimise the loading on the next segments [85]. The PI is a novel and complex concept for the future of supply chain management and it will probably be based on and enabled by a smart IoT system [86]. In the context of a smart city with urbanisation characteristics and the increased use of online digital services, a PI-based approach for a freight transport will provide pure and standardised digital data to the future city's software-defined digital controller (i.e., the "city brain"). This data will be an added valuable feed for AI and big data analytics machines of the "city brain" and will support more efficient and optimal decision-making. The PI, in combination with AI, 
will ensure real-time decision-making to provide adaptable city conditions with online communication and connected PI system elements, such as PI-containers (parcels, pallets), PI-movers (PI-trucks, CAVs, UAVs) and PI-hubs (stores, warehouses). This novel and efficient orchestration of the key elements of a logistics system will boost the quest for a smart, sustainable and resilient city. The PI is the transport and logistics response (or adaptation) to Industry 4.0 [87].

Industry 4.0 or the Fourth Industrial Revolution (per Alexopoulos et al. [88]) started as a German strategic initiative for pioneering manufacturing and has morphed into a transformative paradigm representing the computerisation, automation, digitisation and informisation of industrial systems that includes enabling technologies, such as the Cyber-Physical Systems (CPS), the IoT, Enterprise Resource Planning (ERP) and cloud computing [89-93]. According to Lom et al. [94], other important aspects of Industry 4.0 and key elements of the smart city initiative are the Internet of Services (IoS), which includes intelligent transport and logistics (smart mobility, smart logistics) in particular, as well as the Internet of Energy (IoE), which determines how natural resources (electricity, water, oil) can be used appropriately.

In terms of a bibliography, the IoT, PI and Industry 4.0 are widely covered primarily from a technical and computer engineering perspective; over 53,000, 10,500 and 26,000 Scopus-indexed research outputs, respectively, are currently available to readers. Nonetheless, the current literature still lacks efforts to systematically review the state of the art of these paradigm-shifting initiatives in relation to smart city developments [95].

\section{Definitions and Conclusions}

Despite an abundance of quality research studies with a conceptual (or review-based) character that have tried over time to express, describe and prioritise the diverse, versatile and dynamic dimensions incorporated in each of the themes presented in our paper, including AI (e.g., [96-100]), smart city (e.g., [101-105]), CAVs (e.g., [106-109]), UAVs and PAVs (e.g., [110-113]), MaaS (e.g., [114-117]), IoT (e.g., [118-121]), PI (e.g., [122-125]) and Industry 4.0 (e.g., [126-129]), there is as yet no clear and universally approved set of definitions that critically underpins the nexus of AI, transport and the smart city.

After contextualising the diverse pieces of the future AI-centric transport eco-system of the smart city and linking them together, this paper will now try to provide thorough and systematic definitions for all of them. Table 2 provides an all-in-one reference point for the multidisciplinary audience of city science scholars interested in this topical agenda. This would hopefully increase the visibility and access of the still scarcely studied, in its totality at least, nexus of AI-transport-smart city.

The present work recognises the transformative ability of AI when it comes to the smart city context and how it can be a paradigm-shifting force that will revolutionise mobility in an unprecedented way. However, at the same time, it acknowledges that the machine-oriented identity of the new smart mobility paradigm needs to operate within a responsible, sustainable and user-centred architectural framework that "understands" and "satisfies" the human user, the markets and the society as a whole. The promise of an autonomous, connected, shared and digitised transport service provision is not enough if it does not facilitate efforts that lead to improved environmental conservation, resource efficiency, productivity gains, social inclusion, integration, health and wellbeing. People need to believe that a change could be genuinely beneficial for the many, that they can become active and engaged participants of the new urban eco-system, and that they can sensibly utilise the opportunities provided by the AI-transport-smart city nexus. For this to be achieved, as in every socio-technical transition [130-132], creating trust is the key. 
Table 2. AI-transport-smart city nexus definitions: The lexicon of smart mobility.

\begin{tabular}{|c|c|}
\hline Smart Transport Components & Definitions \\
\hline Artificial Intelligence (AI) & $\begin{array}{l}\text { AI refers to a machine's ability to simulate the human mind by interpreting data it } \\
\text { receives from its environment, learning from them and using that learning to } \\
\text { successfully complete tasks, even in the most unexpected and novel scenarios. }\end{array}$ \\
\hline Smart City & $\begin{array}{l}\text { Smart cities are those urban landscapes with the ability to embrace an integrated } \\
\text { brand of autonomous, connected, shared, digital and cloud-based technologies in } \\
\text { their strategic decision-making and operations to become more sustainable, } \\
\text { creative, informed, cost-efficient and people-focused. }\end{array}$ \\
\hline $\begin{array}{c}\text { Connected and Autonomous } \\
\text { Vehicles (CAVs) }\end{array}$ & $\begin{array}{l}\text { A CAV is any vehicle that can understand its surroundings, move, navigate and } \\
\text { behave responsibly without human input, and at the same time has connectivity } \\
\text { functions enabling it to be proactive, cooperative, well-informed and coordinated. }\end{array}$ \\
\hline Unmanned Aerial Vehicles (UAVs) & $\begin{array}{l}\text { UAVs (also commonly known as drones) are smart aircrafts that can fly without the } \\
\text { onboard presence of pilots and can provide robust air transport solutions for the } \\
\text { provision of improved military, policing and commercial services. }\end{array}$ \\
\hline Personal Aerial Vehicles (PAVs) & $\begin{array}{l}\text { PAVs are flying people-movers, bridging the gap between scheduled airliners and } \\
\text { ground transport, offering unprecedented levels of fast, on-demand urban mobility } \\
\text { by making use of the free air space. }\end{array}$ \\
\hline Mobility-as-a-Service (MaaS) & $\begin{array}{l}\text { MaaS is a system that offers multimodal packages of personalised mobility that will } \\
\text { replace privately owned vehicles through the use of an all-in-one digital platform } \\
\text { that is capable of providing integrated journey planning, booking, smart ticketing } \\
\text { and real-time information services on a subscription or "pay-as-you-go" basis. }\end{array}$ \\
\hline Internet of Things (IoT) & $\begin{array}{c}\text { The IoT is a connectivity paradigm that empowers objects of everyday life to hear, } \\
\text { see, listen and interpret streams of big data and communicate with one another and } \\
\text { with users through integrated cloud technologies, software, sensors and } \\
\text { human-machine interfaces. }\end{array}$ \\
\hline Physical Internet (PI or $\pi$ ) & $\begin{array}{l}\text { The PI is a global concept for sustainable and efficient multimodal freight } \\
\text { transportation and logistics that optimises the movement, storage, supply and } \\
\text { usage of physical objects through the use of digital, automated, interconnected and } \\
\text { big data technologies. }\end{array}$ \\
\hline Industry 4.0 & $\begin{array}{l}\text { Industry } 4.0 \text { is a transformative paradigm representing the computerisation, } \\
\text { automation, digitisation and informisation of industrial systems through the use of } \\
\text { technologies like Cyber-Physical Systems and the Internet of Things. }\end{array}$ \\
\hline
\end{tabular}

Trust should be built through information provision, awareness campaigning, research and development investments, systematic trialing and piloting exercises and strategically designed incremental implementation. Risks and poisonous side-effects, such as the possible increase of motor traffic through the creation of more occupied and (scarily) unoccupied CAV trips supported by a flawed MaaS business model that may still be primarily car-oriented should be eliminated for any techno-centric transition to take off and maximise its potential. Intelligent innovation should also have equally significant socio-centric dimensions.

Thus, it should be expected that the transition to the next mobility paradigm that will naturally match the needs of the smart city will be lengthy, diverse and slow-paced with high levels of complexity and uncertainty. Forecasting may not always be accurate in such a dynamic environment as the one of the smart city. The successful application of AI requires a good understanding of the relationships between $\mathrm{AI}$ and data on one hand, and transportation system characteristics and variables on the other hand [5], such that even if the tools are readily available, change is not straightforward. Making significant changes to an era defined by the human-driven, conventionally fuelled, privately owned, unconnected and ground-based vehicle and its colossal impact on the urban development that dictated how cities have been designed and built for over a century requires a strategic approach based on determination, adaptability and flexibility. Changes in mobility provision cannot be rushed unless technology, legislation, educational and moral frameworks supporting them are all in place and are robust and mature enough to withstand a stratum of challenges, including unknown and unprecedented ones. 
It should be clear that CAVs, UAVs, PAVs, MaaS and their enablers-AI, IoT and PI-are not a panacea that will repair everything that is wrong with the notions and practicalities of urban mobility and the smart city. Despite their transformative powers, these inspiring pillars of the forthcoming travel universe cannot address all the problems that built environments and transport networks face now and may face in the future on their own. Instead, they should be viewed as complementary pieces of the multi-dimensional and interdisciplinary puzzle that smart city really is, and should be coupled, as far as transport goes, with TOD, automated public transport, travel-demand management tools and traffic-calming measures.

We must also appreciate that the smart city narrative in its totality is not exclusively about transport, but has energy, telecommunication, waste management, food supply, water and wastewater, infrastructure, smart building, public safety, business and industrial dimensions that need to be equally catered for. However, AI, with its instrumentation and control, connectivity, interoperability, security and privacy, data management, cloud computing and analytics functions, can again be a vehicle for positive change in all the key ingredients that make up for the complete smart city framework. Finally, in line with Komninos [133], this work highlights that the impact of smart cities reaches far beyond the domain of cities per se, as it influences the challenges of global competitiveness, sustainability and climate change, inclusion and employment.

Author Contributions: Conceptualisation: A.N.; Formal analysis: A.N., K.M., E.T.N. and D.K.; Methodology: A.N., K.M., E.T.N. and D.K.; Writing—original draft: A.N.; Writing—review \& editing: A.N., K.M., E.T.N. and D.K. All authors have read and agreed to the published version of the manuscript.

Funding: This research work is not directly linked to any particular funding initiative.

Conflicts of Interest: The authors declare no conflict of interest.

\section{References}

1. Kaplan, A.; Haenlein, M. Siri, Siri, in my hand: Who's the fairest in the land? On the interpretations, illustrations, and implications of artificial intelligence. Bus. Horiz. 2019, 62, 15-25. [CrossRef]

2. Gurkaynak, G.; Yilmaz, I.; Haksever, G. Stifling artificial intelligence: Human perils. Comput. Law Secur. Rev. 2016, 32, 749-758. [CrossRef]

3. Everitt, T.; Hutter, M. Universal artificial intelligence. In Foundations of Trusted Autonomy; Springer: Cham, Switzerland, 2018; pp. 15-46.

4. Li, L.; Lin, Y.L.; Zheng, N.N.; Wang, F.Y.; Liu, Y.; Cao, D.; Wang, K.; Huang, W.L. Artificial intelligence test: A case study of intelligent vehicles. Artif. Intell. Rev. 2018, 50, 441-465. [CrossRef]

5. Abduljabbar, R.; Dia, H.; Liyanage, S.; Bagloee, S.A. Applications of artificial intelligence in transport: An overview. Sustainability 2019, 11, 189. [CrossRef]

6. Miles, J.C.; Walker, A.J. The potential application of artificial intelligence in transport. IEEE Proc. Intell. Transp. Syst. 2006, 153, 183-198. [CrossRef]

7. Knowles, R.D.; Ferbrache, F.; Nikitas, A. Transport's historical, contemporary and future role in shaping urban development: Re-evaluating transit oriented development. Cities 2020, 99, 102607. [CrossRef]

8. Knowles, R.D. Transport shaping space: Differential collapse in time-space. J. Transp. Geogr. 2006, 14, 407-425. [CrossRef]

9. Alessandrini, A.; Campagna, A.; Delle Site, P.; Filippi, F.; Persia, L. Automated vehicles and the rethinking of mobility and cities. Transp. Res. Procedia 2015, 5, 145-160. [CrossRef]

10. Amditis, A.; Lytrivis, P. Towards Automated Transport Systems: European Initiatives, Challenges and the Way Forward. In Road Vehicle Automation 2; Lecture Notes in Mobility; Meyer, G., Beiker, S., Eds.; Springer: Cham, Switzerland, 2015.

11. Albino, V.; Berardi, U.; Dangelico, R.M. Smart cities: Definitions, dimensions, performance, and initiatives. J. Urban Technol. 2015, 22, 3-21. [CrossRef]

12. Giyenko, A.; Im Cho, Y. Intelligent UAV in smart cities using IoT. In Proceedings of the 2016 16th International Conference on Control, Automation and Systems (ICCAS), Gyeongju, Korea, 16-19 October 2016; pp. 207-210.

13. Lyons, G. Getting smart about urban mobility-aligning the paradigms of smart and sustainable. Transp. Res. Part A Policy Pract. 2018, 115, 4-14. [CrossRef] 
14. Ahvenniemi, H.; Huovila, A.; Pinto-Seppä, I.; Airaksinen, M. What are the differences between sustainable and smart cities? Cities 2017, 60, 234-245. [CrossRef]

15. Komninos, N.; Tsarchopoulos, P.; Kakderi, C. New services design for smart cities: A planning roadmap for user-driven innovation. In Proceedings of the 2014 ACM International Workshop on Wireless and Mobile Technologies for Smart Cities, Philadelphia, PA, USA, 11-14 August 2014; pp. 29-38.

16. Docherty, I.; Marsden, G.; Anable, J. The governance of smart mobility. Transp. Res. Part A Policy Pract. 2018, 115, 114-125. [CrossRef]

17. Milakis, D.; Van Arem, B.; Van Wee, B. Policy and society related implications of automated driving: A review of literature and directions for future research. J. Intell. Transp. Syst. 2017, 21, 324-348. [CrossRef]

18. Papa, E.; Ferreira, A. Sustainable accessibility and the implementation of automated vehicles: Identifying critical decisions. Urban Sci. 2018, 2, 5. [CrossRef]

19. Thomopoulos, N.; Nikitas, A. Smart Urban Mobility Futures: Editorial for Special Issue. Int. J. Automot. Technol. Manag. 2019, 19, 1-9.

20. Nikitas, A.; Tchouamou Njoya, E.; Dani, S. Examining the myths of connected and autonomous vehicles: Analysing the pathway to a driverless mobility paradigm. Int. J. Automot. Technol. Manag. 2019, 19, 10-30. [CrossRef]

21. Nikitas, A.; Kougias, I.; Alyavina, E.; Njoya Tchouamou, E. How can autonomous and connected vehicles, electromobility, BRT, hyperloop, shared use mobility and mobility-as-a-service shape transport futures for the context of smart cities? Urban Sci. 2017, 1, 36. [CrossRef]

22. Barmpounakis, E.N.; Vlahogianni, E.I.; Golias, J.C. Unmanned Aerial Aircraft Systems for transportation engineering: Current practice and future challenges. Int. J. Transp. Sci. Technol. 2016, 5, 111-122. [CrossRef]

23. Bakogiannis, E.; Kyriakidis, C.; Zafeiris, V. Using Unmanned Aerial Vehicles (UAVs) to analyze the urban environment. Eur. J. Eng. Form. Sci. 2019, 3, 20-28. [CrossRef]

24. Hofmann, E.; Rüsch, M. Industry 4.0 and the current status as well as future prospects on logistics. Comput. Ind. 2017, 89, 23-34. [CrossRef]

25. Ingwersen, P.; Serrano-López, A.E. Smart city research 1990-2016. Scientometrics 2018, 117, 1205-1236. [CrossRef]

26. Zear, A.; Singh, P.K.; Singh, Y. Intelligent transport system: A progressive review. Indian J. Sci. Technol. 2016, 9, 1-8. [CrossRef]

27. Firnkorn, J.; Müller, M. Free-floating electric carsharing-fleets in smart cities: The dawning of a post-private car era in urban environments? Environ. Sci. Policy 2015, 45, 30-40. [CrossRef]

28. Gandia, R.; Antonialli, F.; Cavazza, B.H.; Neto, A.M.; De Lima, D.A.; Sugano, J.Y.; Nicolai, I.; Zambalde, A.L. Autonomous vehicles: Scientometric and bibliometric review. Transp. Rev. 2019, 39, 9-28. [CrossRef]

29. Lu, N.; Cheng, N.; Zhang, N.; Shen, X.; Mark, J.W. Connected vehicles: Solutions and challenges. IEEE Internet Things J. 2014, 1, 289-299. [CrossRef]

30. Chehri, A.; Mouftah, H.T. Autonomous vehicles in the sustainable cities, the beginning of a green adventure. Sustain. Cities Soc. 2019, 51, 101751. [CrossRef]

31. Fagnant, D.J.; Kockelman, K. Preparing a nation for autonomous vehicles: Opportunities, barriers and policy recommendations. Transp. Res. Part A Policy Pract. 2015, 77, 167-181. [CrossRef]

32. Thomopoulos, N.; Givoni, M. The autonomous car-A blessing or a curse for the future of low carbon mobility? An exploration of likely vs. desirable outcomes. Eur. J. Futures Res. 2015, 3, 14. [CrossRef]

33. Gavanas, N. Autonomous Road Vehicles: Challenges for Urban Planning in European Cities. Urban Sci. 2019, 3, 61. [CrossRef]

34. De Almeida Correia, G.H.; Milakis, D.; van Arem, B.; Hoogendoorn, R. Vehicle automation and transport system performance. In Handbook on Transport and Urban Planning in the Developed World; Edward Elgar Publishing: Cheltenham, UK, 2016; pp. 498-516.

35. Bansal, P.; Kockelman, K.M. Are we ready to embrace connected and self-driving vehicles? A case study of Texans. Transportation 2018, 45, 641-675. [CrossRef]

36. Milakis, D. Long-term implications of automated vehicles: An introduction. Transp. Rev. 2019, 39, 1-8. [CrossRef]

37. Sochor, J.; Nikitas, A. Vulnerable users' perceptions of transport technologies. Proceedings of the Institution of Civil Engineers. Urban Des. Plan. 2016, 169, 154-162.

38. Kougias, I.; Szabó, S.; Nikitas, A.; Theodossiou, N. Sustainable energy modelling of non-interconnected Mediterranean islands. Renew. Energy 2019, 133, 930-940. [CrossRef] 
39. Kougias, I.; Nikitas, A.; Thiel, C.; Szabó, S. Clean energy and transport pathways for islands: A stakeholder analysis using Q method. Transp. Res. Part D Transp. Environ. 2020, 78, 102180. [CrossRef]

40. Nikitas, A. Connected and Autonomous Vehicles: Priorities for Policy and Planning. In Encyclopedia of Transportation; Vickerman, R., Ed.; Elsevier: Amsterdam, The Netherlands, 2020; in press.

41. Talebian, A.; Mishra, S. Predicting the adoption of connected autonomous vehicles: A new approach based on the theory of diffusion of innovations. Transp. Res. Part C Emerg. Technol. 2018, 95, 363-380. [CrossRef]

42. Chao, H.; Cao, Y.; Chen, Y. Autopilots for small unmanned aerial vehicles: A survey. Int. J. Control Autom. Syst. 2010, 8, 36-44. [CrossRef]

43. Zeng, Y.; Zhang, R.; Lim, T.J. Wireless communications with unmanned aerial vehicles: Opportunities and challenges. IEEE Commun. Mag. 2016, 54, 36-42. [CrossRef]

44. Gupta, S.G.; Ghonge, D.; Jawandhiya, P.M. Review of unmanned aircraft system (UAS). Int. J. Adv. Res. Comput. Eng. Technol. 2013, 2, 1646-1658. [CrossRef]

45. Mohammed, F.; Idries, A.; Mohamed, N.; Al-Jaroodi, J.; Jawhar, I. UAVs for smart cities: Opportunities and challenges. In Proceedings of the 2014 International Conference on Unmanned Aircraft Systems (ICUAS), Orlando, FL, USA, 27-30 May 2014; pp. 267-273.

46. Menouar, H.; Guvenc, I.; Akkaya, K.; Uluagac, A.S.; Kadri, A.; Tuncer, A. UAV-enabled intelligent transportation systems for the smart city: Applications and challenges. IEEE Commun. Mag. 2017, 55, 22-28. [CrossRef]

47. Mohamed, N.; Al-Jaroodi, J.; Jawhar, I.; Idries, A.; Mohammed, F. Unmanned aerial vehicles applications in future smart cities. Technol. Forecast. Soc. Chang. 2018, 153, 119293. [CrossRef]

48. Fleischer, T.; Meyer-Soylu, S.; Schippl, J.; Decker, M. Personal aerial transportation systems (PATS)-A potential solution for the urban mobility challenges? Futures 2019, 109, 50-62. [CrossRef]

49. Balac, M.; Vetrella, A.R.; Rothfeld, R.; Schmid, B. Demand estimation for aerial vehicles in urban settings. IEEE Intell. Transp. Syst. Mag. 2019, 11, 105-116. [CrossRef]

50. Liu, Y.; Kreimeier, M.; Stumpf, E.; Zhou, Y.; Liu, H. Overview of recent endeavors on personal aerial vehicles: A focus on the US and Europe led research activities. Prog. Aerosp. Sci. 2017, 91, 53-66. [CrossRef]

51. Lichfield, G. When Will We Have Flying Cars? Maybe Sooner Than You Think. MIT Technology Review. 2019. Available online: https://www.technologyreview.com/s/612891/when-will-we-have-flying-cars-maybesooner-than-you-think/ (accessed on 5 March 2020).

52. Karlsson, I.M.; Sochor, J.; Strömberg, H. Developing the 'Service' in Mobility as a Service: Experiences from a field trial of an innovative travel brokerage. Transp. Res. Procedia 2016, 14, 3265-3273. [CrossRef]

53. Sochor, J.; Strömberg, H.; Karlsson, I.M. Implementing mobility as a service: Challenges in integrating user, commercial, and societal perspectives. Transp. Res. Rec. 2015, 2536, 1-9. [CrossRef]

54. Sochor, J.; Karlsson, I.M.; Strömberg, H. Trying out mobility as a service: Experiences from a field trial and implications for understanding demand. Transp. Res. Rec. 2016, 2542, 57-64. [CrossRef]

55. Alonso-González, M.J.; Hoogendoorn-Lanser, S.; van Oort, N.; Cats, O.; Hoogendoorn, S. Drivers and barriers in adopting Mobility as a Service (MaaS)-A latent class cluster analysis of attitudes. Transp. Res. Part A Policy Pract. 2020, 132, 378-401. [CrossRef]

56. Fioreze, T.; De Gruijter, M.; Geurs, K. On the likelihood of using Mobility-as-a-Service: A case study on innovative mobility services among residents in the Netherlands. Case Stud. Transp. Policy 2019, 7, 790-801. [CrossRef]

57. Hirschhorn, F.; Paulsson, A.; Sørensen, C.H.; Veeneman, W. Public transport regimes and mobility as a service: Governance approaches in Amsterdam, Birmingham, and Helsinki. Transp. Res. Part A Policy Pract. 2019, 130, 178-191. [CrossRef]

58. Smith, G.; Sochor, J.; Karlsson, I.M. Mobility as a Service: Development scenarios and implications for public transport. Res. Transp. Econ. 2018, 69, 592-599. [CrossRef]

59. Hensher, D.A. Future bus transport contracts under a mobility as a service (MaaS) regime in the digital age: Are they likely to change? Transp. Res. Part A Policy Pract. 2017, 98, 86-96. [CrossRef]

60. Polydoropoulou, A.; Pagoni, I.; Tsirimpa, A.; Roumboutsos, A.; Kamargianni, M.; Tsouros, I. Prototype business models for Mobility-as-a-Service. Transp. Res. Part A Policy Pract. 2020, 131, 149-162. [CrossRef]

61. Matyas, M.; Kamargianni, M. The potential of mobility as a service bundles as a mobility management tool. Transportation 2019, 46, 1951-1968. [CrossRef] 
62. Xie, Y.; Danaf, M.; Azevedo, C.L.; Akkinepally, A.P.; Atasoy, B.; Jeong, K.; Seshadri, R.; Ben-Akiva, M. Behavioral modeling of on-demand mobility services: General framework and application to sustainable travel incentives. Transportation 2019, 46, 2017-2039. [CrossRef]

63. Schikofsky, J.; Dannewald, T.; Kowald, M. Exploring motivational mechanisms behind the intention to adopt mobility as a service (MaaS): Insights from Germany. Transp. Res. Part A Policy Pract. 2020, 131, $296-312$. [CrossRef]

64. Pangbourne, K.; Mladenović, M.N.; Stead, D.; Milakis, D. Questioning Mobility as a Service: Unanticipated implications for society and governance. Transp. Res. Part A Policy Pract. 2020, 131, 35-49. [CrossRef]

65. Chang, S.J.; Chen, H.Y.; Chen, H.C. Mobility as a service policy planning, deployments and trials in Taiwan. Iatss Res. 2019, 43, 210-218. [CrossRef]

66. Mulley, C.; Ho, C.; Balbontin, C.; Hensher, D.; Stevens, L.; Nelson, J.D.; Wright, S. Mobility as a service in community transport in Australia: Can it provide a sustainable future? Transp. Res. Part A Policy Pract. 2020, 131, 107-122. [CrossRef]

67. Arias-Molinares, D.; García-Palomares, J.C. The Ws of MaaS: Understanding mobility as a service from a literature review. IATSS Res. 2020, in press. [CrossRef]

68. Bothos, E.; Magoutas, B.; Arnaoutaki, K.; Mentzas, G. Leveraging Blockchain for Open Mobility-as-a-Service Ecosystems. In Proceedings of the IEEE/WIC/ACM International Conference on Web Intelligence-Companion Volume, Thessaloniki, Greece, 14-17 October 2019; pp. 292-296.

69. Lyons, G.; Hammond, P.; Mackay, K. Reprint of: The importance of user perspective in the evolution of MaaS. Transp. Res. Part A Policy Pract. 2020, 131, 20-34. [CrossRef]

70. Kamargianni, M.; Li, W.; Matyas, M.; Schäfer, A. A critical review of new mobility services for urban transport. Transp. Res. Procedia 2016, 14, 3294-3303. [CrossRef]

71. Stocker, A.; Shaheen, S. Shared Automated Mobility: Early Exploration and Potential Impacts. Road Veh. Autom. 2018, 4, 125-139.

72. Mulley, C. Mobility as a Services (MaaS)—Does it have critical mass? Transp. Rev. 2017, 37, 247-251. [CrossRef]

73. Tinnilä, M.; Kallio, J. Impact of future trends on personal mobility services. Int. J. Automot. Technol. Manag. 2015, 15, 401-417. [CrossRef]

74. Jittrapirom, P.; Marchau, V.; van der Heijden, R.; Meurs, H. Future implementation of Mobility as a Service (MaaS): Results of an international Delphi study. Travel Behav. Soc. 2018, in press. [CrossRef]

75. Wortmann, F.; Flüchter, K. Internet of things. Bus. Inf. Syst. Eng. 2015, 57, 221-224. [CrossRef]

76. Zanella, A.; Bui, N.; Castellani, A.; Vangelista, L.; Zorzi, M. Internet of things for smart cities. IEEE Internet Things J. 2014, 1, 22-32. [CrossRef]

77. Atzori, L.; Iera, A.; Morabito, G. The internet of things: A survey. Comput. Netw. 2010, 54, $2787-2805$. [CrossRef]

78. Kim, T.H.; Ramos, C.; Mohammed, S. Smart city and IoT. Future Gener. Comput. Syst. 2017, 76, 159-162. [CrossRef]

79. Rathore, M.M.; Ahmad, A.; Paul, A.; Rho, S. Urban planning and building smart cities based on the internet of things using big data analytics. Comput. Netw. 2016, 101, 63-80. [CrossRef]

80. Harmon, R.R.; Castro-Leon, E.G.; Bhide, S. Smart cities and the Internet of Things. In Proceedings of the 2015 Portland International Conference on Management of Engineering and Technology (PICMET), Portland, OR, USA, 2-6 August 2015; pp. 485-494.

81. Mohanty, S.P.; Choppali, U.; Kougianos, E. Everything you wanted to know about smart cities: The internet of things is the backbone. IEEE Consum. Electron. Mag. 2016, 5, 60-70. [CrossRef]

82. Guerrero-Ibanez, J.A.; Zeadally, S.; Contreras-Castillo, J. Integration challenges of intelligent transportation systems with connected vehicle, cloud computing, and internet of things technologies. IEEE Wirel. Commun. 2015, 22, 122-128. [CrossRef]

83. Crainic, T.G.; Montreuil, B. Physical internet enabled hyperconnected city logistics. Transp. Res. Procedia 2016, 12, 383-398. [CrossRef]

84. Montreuil, B. Toward a Physical Internet: Meeting the global logistics sustainability grand challenge. Logist. Res. 2011, 3, 71-87. [CrossRef]

85. Montreuil, B.; Rougès, J.F.; Cimon, Y.; Poulin, D. The physical internet and business model innovation. Technol. Innov. Manag. Rev. 2012, 2, 32-37. [CrossRef] 
86. Karampatzakis, D.; Avramidis, G.; Kiratsa, P.; Tseklidis, I.; Oikonomidis, C. A Smart Cargo Bike for the Physical Internet enabled by RFID and LoRaWAN. In Proceedings of the 2019 Panhellenic Conference on Electronics \& Telecommunications (PACET), Volos, Greece, 8-9 November 2019; pp. 1-4.

87. Maslarić, M.; Nikoličić, S.; Mirčetić, D. Logistics response to the industry 4.0: The physical internet. Open Eng. 2016, 6, 511-517.

88. Alexopoulos, K.; Makris, S.; Xanthakis, V.; Sipsas, K.; Chryssolouris, G. A Concept for Context-aware Computing in Manufacturing: The White Goods Case. Int. J. Comput. Integr. Manuf. 2016, 29, 839-849. [CrossRef]

89. Xu, L.D.; Xu, E.L.; Li, L. Industry 4.0: State of the art and future trends. Int. J. Prod. Res. 2018, 56, $2941-2962$. [CrossRef]

90. Lu, Y. Industry 4.0: A survey on technologies, applications and open research issues. J. Ind. Inf. Integr. 2017, 6, 1-10. [CrossRef]

91. Zhong, R.Y.; Xu, X.; Klotz, E.; Newman, S.T. Intelligent manufacturing in the context of industry 4.0: A review. Engineering 2017, 3, 616-630. [CrossRef]

92. Lasi, H.; Thomas, P.F.; Hoffmann, M. Industry 4.0. Bus. Inf. Syst. Eng. 2014, 6, 239-242. [CrossRef]

93. Sung, T.K. Industry 4.0: A Korea perspective. Technol. Forecast. Soc. Chang. 2018, 132, 40-45. [CrossRef]

94. Lom, M.; Pribyl, O.; Svitek, M. Industry 4.0 as a part of smart cities. In Proceedings of the 2016 Smart Cities Symposium Prague (SCSP), Prague, Czech Republic, 26-27 May 2016; pp. 1-6.

95. Liao, Y.; Deschamps, F.; Loures, E.D.F.R.; Ramos, L.F.P. Past, present and future of Industry 4.0-a systematic literature review and research agenda proposal. Int. J. Prod. Res. 2017, 55, 3609-3629. [CrossRef]

96. Lehman-Wilzig, S.N. Frankenstein unbound: Towards a legal definition of artificial intelligence. Futures 1981, 13, 442-457. [CrossRef]

97. Li, D.; Du, Y. Artificial Intelligence with Uncertainty; CRC Press: Boca Raton, FL, USA, 2017.

98. Guo, K.; Lu, Y.; Gao, H.; Cao, R. Artificial Intelligence-Based Semantic Internet of Things in a User-Centric Smart City. Sensors 2018, 18, 1341. [CrossRef]

99. Simon, J.P. Artificial intelligence: Scope, players, markets and geography. Digit. PolicyRegul. Gov. 2019, 21, 208-237. [CrossRef]

100. Haenlein, M.; Kaplan, A. A brief history of artificial intelligence: On the past, present, and future of artificial intelligence. Calif. Manag. Rev. 2019, 61, 5-14. [CrossRef]

101. Angelidou, M. Smart cities: A conjuncture of four forces. Cities 2015, 47, 95-106. [CrossRef]

102. Caragliu, A.; Del Bo, C.; Nijkamp, P. Smart cities in Europe. J. Urban Technol. 2011, 18, 65-82. [CrossRef]

103. Dameri, R.P. Searching for smart city definition: A comprehensive proposal. Int. J. Comput. Technol. 2013, 11, 2544-2551. [CrossRef]

104. Neirotti, P.; De Marco, A.; Cagliano, A.C.; Mangano, G.; Scorrano, F. Current trends in Smart City initiatives: Some stylised facts. Cities 2014, 38, 25-36. [CrossRef]

105. Grossi, G.; Pianezzi, D. Smart cities: Utopia or neoliberal ideology? Cities 2017, 69, 79-85. [CrossRef]

106. Montanaro, U.; Dixit, S.; Fallah, S.; Dianati, M.; Stevens, A.; Oxtoby, D.; Mouzakitis, A. Towards connected autonomous driving: Review of use-cases. Veh. Syst. Dyn. 2019, 57, 779-814. [CrossRef]

107. Uhlemann, E. Time for autonomous vehicles to connect [connected vehicles]. IEEE Veh. Technol. Mag. 2018, 13, 10-13. [CrossRef]

108. Mahmassani, H.S. 50th anniversary invited article-Autonomous vehicles and connected vehicle systems: Flow and operations considerations. Transp. Sci. 2016, 50, 1140-1162. [CrossRef]

109. Sumalee, A.; Ho, H.W. Smarter and more connected: Future intelligent transportation system. Iatss Res. 2018, 42, 67-71. [CrossRef]

110. Hassanalian, M.; Abdelkefi, A. Classifications, applications, and design challenges of drones: A review. Prog. Aerosp. Sci. 2017, 91, 99-131. [CrossRef]

111. Qi, F.; Zhu, X.; Mang, G.; Kadoch, M.; Li, W. UAV network and IoT in the sky for future smart cities. IEEE Netw. 2019, 33, 96-101. [CrossRef]

112. Rothfeld, R.; Straubinger, A.; Fu, M.; Al Haddad, C.; Antoniou, C. Urban air mobility. In Demand for Emerging Transportation Systems; Antoniou, C., Efthymiou, D., Chaniotakis, E., Eds.; Elsevier: Amsterdam, The Netherlands, 2020; pp. 267-284.

113. Jensen, O.B. Drone city-power, design and aerial mobility in the age of "smart cities". Geogr. Helv. 2016, 71, 67. [CrossRef] 
114. Utriainen, R.; Pöllänen, M. Review on mobility as a service in scientific publications. Res. Transp. Bus. Manag. 2018, 27, 15-23. [CrossRef]

115. Wong, Y.Z.; Hensher, D.A.; Mulley, C. Mobility as a service (MaaS): Charting a future context. Transp. Res. Part A Policy Pract. 2019, 131, 5-19. [CrossRef]

116. Smith, G.; Sochor, J.; Sarasini, S. Mobility as a service: Comparing developments in Sweden and Finland. Res. Transp. Bus. Manag. 2018, 27, 36-45. [CrossRef]

117. Shaheen, S.; Cohen, A. Mobility on demand (MOD) and mobility as a service (MaaS): Early understanding of shared mobility impacts and public transit partnerships. In Demand for Emerging Transportation Systems; Antoniou, C., Efthymiou, D., Chaniotakis, E., Eds.; Elsevier: Amsterdam, The Netherlands, 2020; pp. 37-59.

118. Gubbi, J.; Buyya, R.; Marusic, S.; Palaniswami, M. Internet of Things (IoT): A vision, architectural elements, and future directions. Future Gener. Comput. Syst. 2013, 29, 1645-1660. [CrossRef]

119. Lee, I.; Lee, K. The Internet of Things (IoT): Applications, investments, and challenges for enterprises. Bus. Horiz. 2015, 58, 431-440. [CrossRef]

120. Atzori, L.; Iera, A.; Morabito, G. Understanding the Internet of Things: Definition, potentials, and societal role of a fast evolving paradigm. Ad Hoc Netw. 2017, 56, 122-140. [CrossRef]

121. Ali, Z.H.; Ali, H.A.; Badawy, M.M. Internet of Things (IoT): Definitions, challenges and recent research directions. Int. J. Comput. Appl. 2015, 128, 37-47.

122. Pan, S.; Ballot, E.; Huang, G.Q.; Montreuil, B. Physical Internet and interconnected logistics services: Research and applications. Int. J. Prod. Res. 2017, 55, 2603-2609. [CrossRef]

123. Sternberg, H.; Norrman, A. The Physical Internet-Review, analysis and future research agenda. Int. J. Phys. Distrib. Logist. Manag. 2017, 47, 736-762. [CrossRef]

124. Mervis, J. The information highway gets physical: The Physical Internet would move goods the way its namesake moves data. Science 2014, 344, 1104-1107. [CrossRef]

125. Landschutzer, C.; Ehrentraut, F.; Jodin, D. Containers for the Physical Internet: Requirements and engineering design related to FMCG logistics. Logist. Res. 2015, 8, 1-22. [CrossRef]

126. Roblek, V.; Meško, M.; Krapež, A. A complex view of industry 4.0. Sage Open 2016, 6, 2158244016653987. [CrossRef]

127. Lee, J.; Bagheri, B.; Kao, H.A. A cyber-physical systems architecture for industry 4.0-based manufacturing systems. Manuf. Lett. 2015, 3, 18-23. [CrossRef]

128. Piccarozzi, M.; Aquilani, B.; Gatti, C. Industry 4.0 in management studies: A systematic literature review. Sustainability 2018, 10, 3821. [CrossRef]

129. Ghobakhloo, M. The future of manufacturing industry: A strategic roadmap toward Industry 4.0. J. Manuf. Technol. Manag. 2018, 29, 910-936. [CrossRef]

130. Hengstler, M.; Enkel, E.; Duelli, S. Applied artificial intelligence and trust-The case of autonomous vehicles and medical assistance devices. Technol. Forecast. Soc. Chang. 2016, 105, 105-120. [CrossRef]

131. Nikitas, A.; Avineri, E.; Parkhurst, G. Understanding the public acceptability of road pricing and the roles of older age, social norms, pro-social values and trust for urban policy-making: The case of Bristol. Cities 2018, 79, 78-91. [CrossRef]

132. Nikitas, A.; Avineri, E.; Parkhurst, G. Older people's attitudes to road charging: Are they distinctive and what are the implications for policy? Transp. Plan. Technol. 2011, 34, 87-108. [CrossRef]

133. Komninos, N. What makes cities intelligent? In Smart Cities; Routledge: Abingdon, UK, 2013; pp. 89-107.

(C) 2020 by the authors. Licensee MDPI, Basel, Switzerland. This article is an open access article distributed under the terms and conditions of the Creative Commons Attribution (CC BY) license (http://creativecommons.org/licenses/by/4.0/). 